\title{
Transmedia Tokoh Wayang pada Budaya Populer (Karakter Gatotkaca pada Komik Garudayana)
}

\author{
Henry Gunawan, Eko Harry Susanto, Nigar Pandrianto \\ henry.915150162@stu.untar.ac.id, ekos@fikom.untar.ac.id,nigarp@fikom.untar.ac.id
}

Fakultas Ilmu Komunikasi Universitas Tarumanagara

\begin{abstract}
Transmedia is a process of translating or an effort to transfer ideas within stories to another media where every element is systematically dispersed to create a unified and coordinated experiences. This study discusses the process that transform wayang character to popular culture which using Gatotkaca from Garudayana comic as a subject of research. The theory that the author uses are oral tradition, transmedia, popular culture, comic, character and symbol. This study uses qualitative approach with discourse analysis and case study methods as a strategy for study. The author also uses interview, observation, literature study, and online surfing as a method of data collection. The result of this study shows that Garudayana is indeed a product of transmedia of Mahabharata story.
\end{abstract}

Keywords: Transmedia, Popular Culture, Comic

\begin{abstract}
Abstrak
Transmedia merupakan sebuah proses penyaduran, translasi, dan upaya untuk menyampaikan gagasan sebuah cerita menjadi bentuk lain. Penelitian ini bertujuan untuk membahas proses transmedia pada tokoh wayang di budaya popular karakter Gatotkaca pada komik Garudayana. Penelitian ini menggunakan landasan teori tradisi lisan, alih wahana, budaya popular, komik, tokoh, dan simbol. Metode penelitian yang digunakan oleh penulis adalah metode kualitatif dengan strategi penelitian analisis wacana dan studi kasus untuk melengkapi pengumpulan data penulis. Penulis melakukan wawancara mendalam, observasi, penelusuran data online, dan studi kepustakaan. Kesimpulan yang didapatkan dari penelitian ini adalah Garudayana merupakan hasil transmedia dari cerita Mahabharata.
\end{abstract}

Kata Kunci: Transmedia, Komik, Budaya Populer

\section{Pendahuluan}

Cerita Mahabharata merupakan sebuah cerita yang sudah dikenal oleh banyak orang dalam berbagai bentuk. Salah satu bentuk media yang menceritakan Mahabharata adalah wayang kulit purwa. Sejalan dengan perkembangan waktu dan teknologi, penceritaan Mahabharata mengalami perubahan bentuk menjadi media lain. Perubahan bentuk penceritaan tersebut merupakan sebuah proses transmedia. Transmedia adalah sebuah kegiatan penerjemahan, penyaduran, dan pemindahan dari satu media ke media lain (Damono, 2018: 9). Salah satu produk budaya populer yang dikenal oleh masyarakat untuk menceritakan Mahabharata adalah dalam bentuk komik wayang.

Komik wayang pada awalnya merupakan sebuah bentuk kritik terhadap budaya barat yang dianggap memiliki gagasan yang berbahaya. Komik wayang merupakan sebuah produk yang menggambarkan kebudayaan nasional (Bonneff, 2008:28). 
Munculnya komik wayang di Indonesia merupakan sebuah produk yang sangat diminati oleh banyak orang hingga saat ini. Garudayana merupakan komik wayang era modern yang terbit pada tahun 2009 dan diciptakan oleh Is Yuniarto.

Dalam penelitian ini, penulis akan mencari tahu bagaimana transmedia pada tokoh wayang pada budaya populer dilakukan. Tokoh wayang yang diteliti oleh penulis adalah Gatotkaca pada komik Garudayana serta untuk melihat bagaimana terjadinya proses transmedia dan melihat perubahan yang terjadi pada karakter Gatotkaca akibat proses transmedia tersebut.

\section{Metode Penelitian}

Metode penelitian yang digunakan oleh penulis untuk penelitian ini adalah metode penelitian kualitatif dengan strategi analisis wacana dan studi kasus untuk melengkapi data-data yang dibutuhkan oleh penulis. Menurut Moelong (2009:8-13) penelitian kualitatif adalah penelitian untuk memahami fenomena tentang apa yang dialami oleh subjek penelitian. Penelitian kualitatif digunakan untuk mendapatkan hasil analisa berupa penggambaran.

Strategi penelitian yang digunakan pada penelitian ini adalah analisis wacana. Menurut Sobur (2006:48) analisis wacana adalah studi tentang struktur pesan dalam komunikasi. Penulis menggunakan strategi analisis wacana untuk menganalisis bahasa dan gambar yang terdapat pada komik Garudayana. Analisis wacana digunakan oleh penulis semata-mata bukan hanya menganalisis bahasanya namun juga dihubungkan dengan konteks (Eriyanto, 2001:7). Penulis juga menggunakan strategi studi kasus. Metode ini digunakan untuk menggali fakta dari berbagai sumber data, dianalisis, dan di interpretasikan untuk mengangkat substansi mendasar dibalik kasus yang diteliti (Gunawan, 2014:114).

Pengumpulan data dilakukan oleh penulis dengan cara wawancara, studi kepustakaan, observasi, dan penelusuran data online. Setelah data berhasil di kumpulkan, penulis mengolah dan menganalisis data. Metode untuk melakukan analisis data menurut Miles dan Huberman (dalam Susanto, 2018:69), dapat dilakukan dengan beberapa proses yaitu: (1) Reduksi data, yang merupakan proses pemilihan, pemusatan perhatian, penyederhanaan, pengabstrakan, dan transformasi kasar catatan lapangan yang dilakukan pada data. (2) Informasi yang dikumpulkan ditarik dan disusun sehingga memberikan kesimpulan dan tindakan. (3) Penarikan kesimpulan pada data yang telah dikumpulkan dan di kaji. Penganalisis mulai mencari pola-pola, kejelasan, konfigurasi alur sebab-akibat, proposisi, dan bendabenda.

\section{Hasil Temuan dan Diskusi}

Saat ini, sejalan dengan perkembangan teknologi, sebuah cerita klasik seperti Mahabharata terus mengalami perubahan bentuk media dan penceritaan. Pada awalnya penceritaan Mahabharata dilakukan secara lisan, kemudian menjadi sebuah tulisan, dan bentuk wayang kulit purwa. Saat ini, penceritaan Mahabharata mengalami proses transmedia hingga menjadi sebuah produk budaya populer yaitu komik Garudayana. Perubahan cara penceritaan ini adalah sebuah tanda bahwa telah terjadi proses transmedia terhadap penceritaan Mahabharata.

Komik Garudayana dapat menjadi sebuah penceritaan Mahabharata karena Garudayana telah berhasil meminjam karakter-karakter yang ada pada cerita 
Mahabharata. Karakter-karakter tersebut merupakan karakter yang sudah dikenal oleh masyarakat luas untuk menjembatani penceritaan Mahabharata yang ingin dibuat oleh pengarang.

Komik Garudayana menceritakan tentang kondisi dunia pewayangan Arcapada, yang kacau balau karena sebuah telur Garuda ditemukan. Karena ada dua belah pihak yang memperebutkan telur Garuda, keluarga Pandawa dan Kurawa.

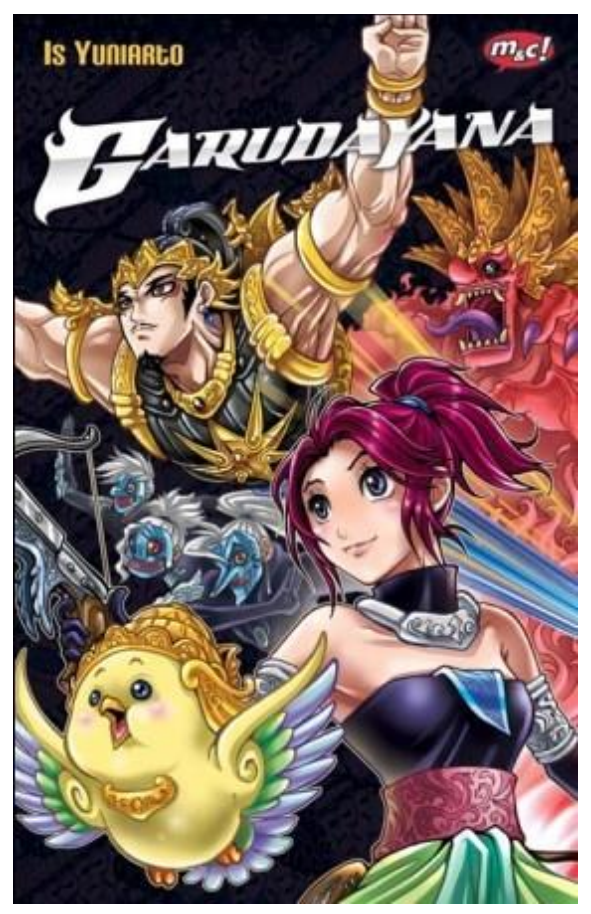

Gambar 1. Sampul Depan Komik Garudayana

(Sumber: https://www.deviantart.com/vanguard-zero/art/Garudayana-Comic-Cover130179534

Meskipun Garudayana meminjam karakter yang ada pada cerita Mahabharata, banyak pengayaan dan pereduksian pada karakter yang dilakukan oleh pengarang untuk menyesuaikan cerita yang akan dibuat. Pengayaan dan pereduksian yang dilakukan oleh pengarang terhadap karaker dilakukan pada aspek visual. Selain meminjam karakter pada cerita Mahabharata, pengarang juga membuat karakter utama yang orisinal sebagai bentuk dari usaha pengarang untuk menceritakan Mahabharata dengan alur yang berbeda. Karakter orisinal yang dibuat untuk komik Garudayana adalah Kinara, yang memiliki latar belakang seorang pemburu harta karun yang secara tidak sengaja bertemu dengan telur Garuda. 


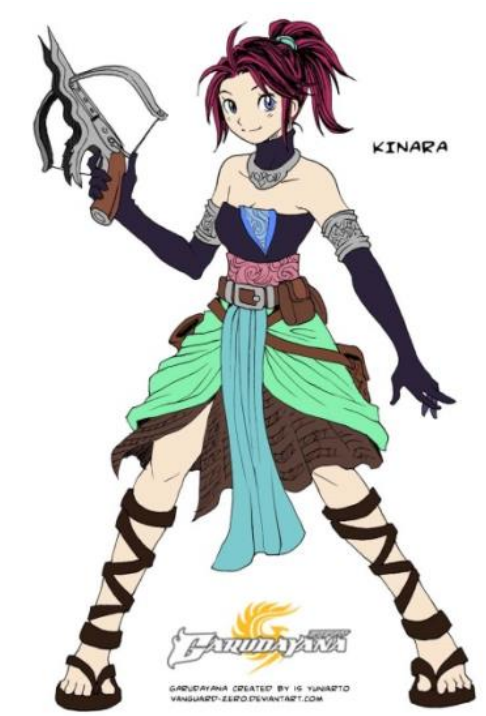

Gambar 2. Kinara

(Sumber: https://www.deviantart.com/vanguard-zero/art/Garudayana-chara-Kinara147210932

Pengayaan pada setting cerita juga dilakukan untuk memperkaya dunia wayang yang dibuat oleh penulis. Contoh dari pengayaan yang dilakukan oleh penulis adalah menggabungkan berbagai kebudayaan yang ada di Indonesia ke dalam dunia wayang Arcapada yang di ciptakan oleh penulis. Salah satu contoh kebudayaan yang dimasukkan ke dalam komik Garudayana adalah lokasi Hutan Kalpataru yang terinspirasi dari bentuk penghargaan yang diberikan oleh pemerintah Indonesia kepada orang atau kelompok atas jasanya melestarikan lingkungan. Bentuk pohon yang ada pada hutan Kalpataru ini memiliki bentuk yang sangat identik dengan bentuk trofi Kalpataru.

Selain hutan Kalpataru, komik Garudayana juga berhasil melakukan pengayaan lain yaitu penambahan karakter Asura sebagai sebuah ras yang melambangkan kejahatan. Pada cerita wayang, Asura digambarkan sebagai raksasa saja. Pada komik Garudayana, Asura memiliki bentuk yang lebih bervariasi. 


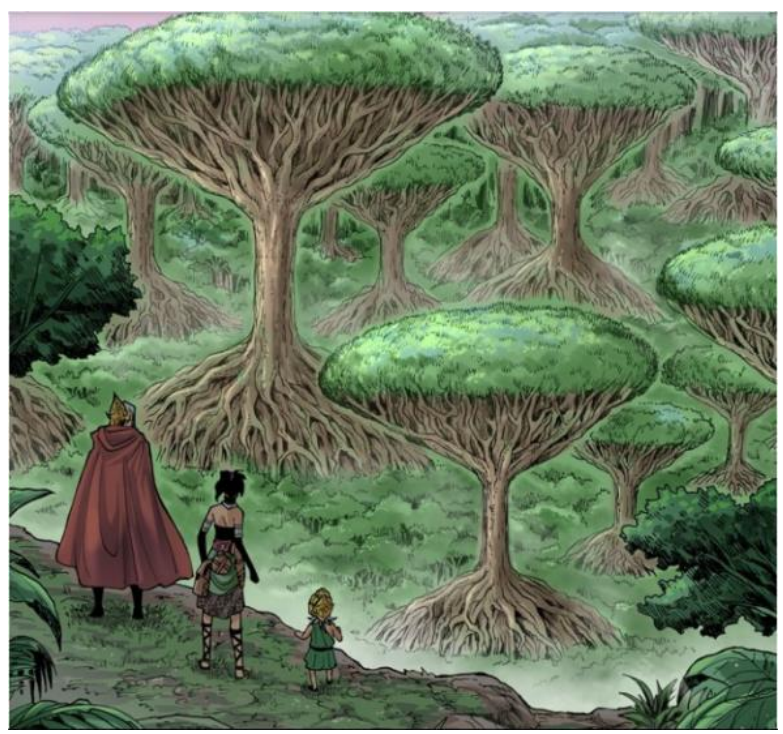

Gambar 3. Hutan Kalpataru

(Sumber: https://www.ciayo.com/id/comic/garudayana/hutan-kalpataru)

Pengayaan pada karakter juga dilakukan oleh pengarang dengan tujuan untuk menarik perhatian pembaca. Salah satu karakter yang mengalami perubahan dan kehilangan identitas sebagai tokoh wayang adalah Arjuna.

Pada komik Garudayana, Arjuna memiliki rambut panjang berwarna putih, memiliki mata berwarna hijau, menggunakan baju berwarna biru, celana panjang hitam, dan alas kaki seperti gladiator, dan membawa busur dan anak panah.

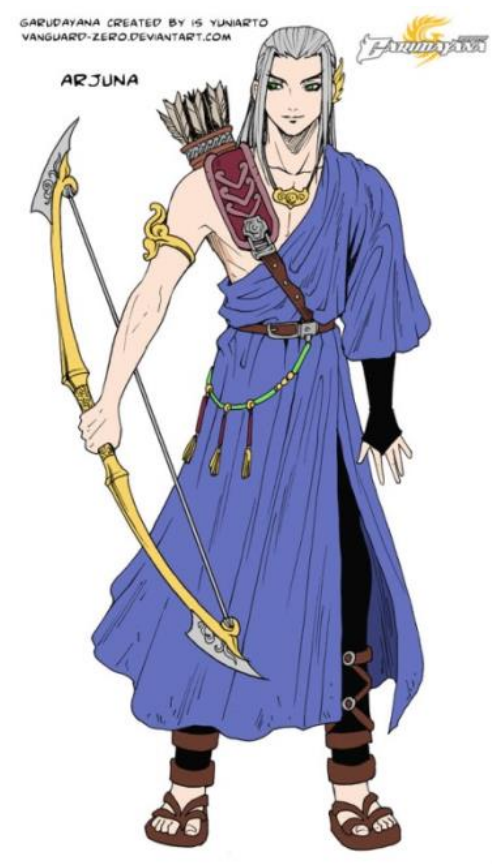

Gambar 4. Arjuna Garudayana

(Sumber: https://www.deviantart.com/vanguard-zero/art/Garudayana-Chara-Arjuna149732781)

Perubahan secara visual ini merupakan salah satu proses transmedia yang dilakukan oleh pengarang dalam menyadurkan karakter pinjaman Mahabharata. Hal yang sama juga terjadi pada karakter Gatotkaca. Meskipun identitas Gatotkaca 
dengan sangat mudah dikenali, namun ada perubahan-perubahan yang dilakukan oleh pengarang terhadap karakter tersebut.

Selain perubahan dalam segi visual, karakter Gatotkaca juga mengalami perubahan pada sifat. Pada cerita wayang memiliki sifat baik seperti sifat pahlawan, pemberani, dan disegani oleh musuh dan juga memiliki sifat buruk seperti mudah marah. Sifat tersebut membuat Gatotkaca secara tidak sengaja membunuh pamannya sendiri (Kaelola, 2010:194). Pada komik Garudayana, pengarang menghilangkan sifat buruk Gatotkaca dengan membuat Gatotkaca hanya memiliki sifat pahlawan saja.

Gatotkaca juga memiliki sifat penolong yang dapat dilihat ketika seorang kakek tua yang ingin menyeberang sebuah jembatan kayu dan terjatuh, Gatotkaca dengan segera menolong kakek tua tersebut.

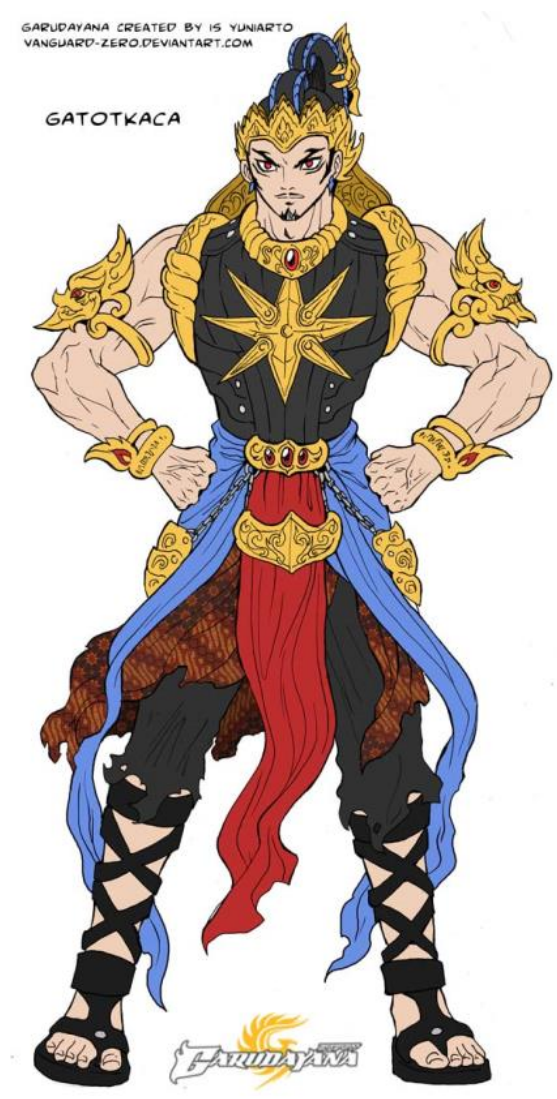

Gambar 5. Gatotkaca Garudayana

(Sumber: https://www.deviantart.com/vanguard-zero/art/Garudayana-chara-

Gatotkaca-147212886) 


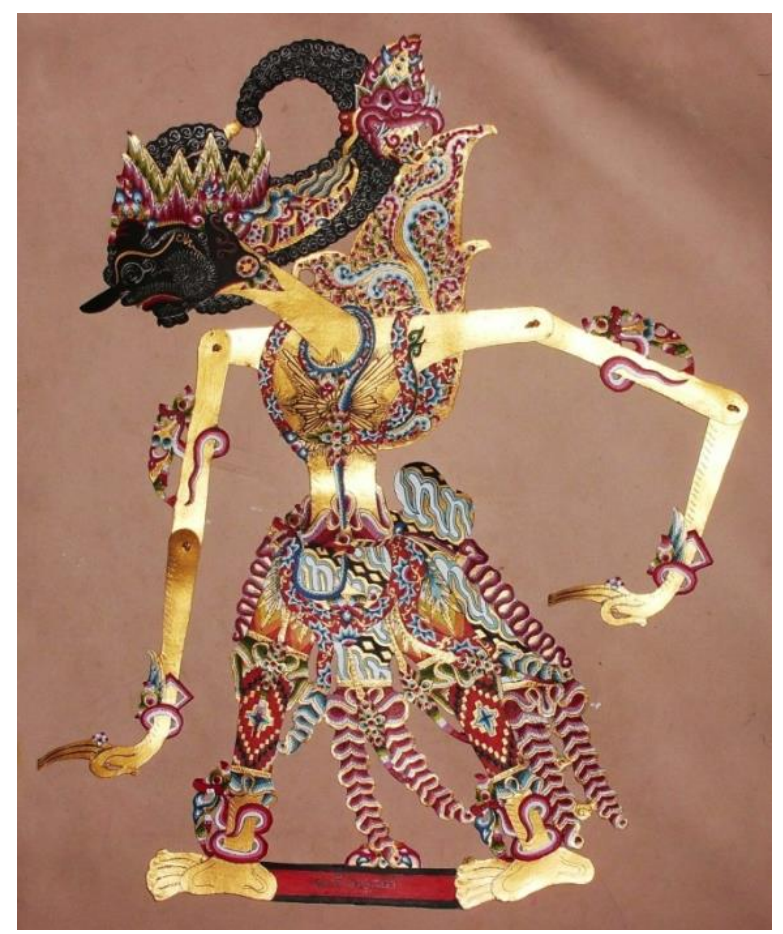

Gambar 6. Wayang Kulit Gatotkaca

(Sumber: https://upload.wikimedia.org/wikipedia/id/6/69/Gatotkaca_Surakarta.JPG)

\section{Simpulan}

Komik Garudayana merupakan sebuah hasil transmedia dari cerita Mahabharata. Kesimpulan ini didapatkan karena adanya proses transmedia yang terlihat seperti adanya peminjaman karakter Mahabharata, penyaduran dan juga perubahan media yang dilakukan oleh komik Garudayana sebagai sebuah media penceritaan Mahabharata.

Akibat dari proses penyaduran yang dilakukan oleh Garudayana, ada pengayaan dan pereduksian yang terjadi pada karakter di komik Garudayana. Pengayaan dan pereduksian tersebut dapat dilihat dalam berbagai bentuk. Perubahan yang paling mudah dilihat adalah perubahan dalam segi visual namun ada perubahan yang terjadi pada latar belakang cerita yang membuat penceritaan Mahabharata pada komik Garudayana semakin kaya.

Perubahan-perubahan tersebut juga dapat dilihat pada karakter Gatotkaca dari visual, sifat, dan personalitas yang berubah mengikuti penyaduran yang dilakukan pada komik Garudayana.

\section{Ucapan Terima Kasih}

Peneliti mengucapkan banyak terima kasih kepada seluruh informan yang telah berkontribusi membantu penulis untuk menyelesaikan penelitian ini, terutama kepada kakak Is Yuniarto sebagai pengarang dari komik Garudayana yang telah bersedia untuk diwawancara. Kedua, kepada Carolus Astabrata, seorang dosen pengajar DKV Universitas Tarumanagara, dan juga peneliti komik yang telah bersedia meluangkan waktunya untuk menjadi informan kunci dalam penelitian ini. Kemudian peneliti juga ingin berterima kasih kepada Louise, Angel, Chelsea, Hendri, Valeri, dan Evelyn yang telah bersedia meluangkan waktunya untuk diwawancara. Peneliti juga 
ingin berterima kasih kepada Dr. Eko Harry Susanto, Drs. M.Si. selaku pembimbing dan juga Nigar Pandrianto S.Sos., M.Si. selaku co-pembimbing yang telah membantu penulis dengan sabar untuk menyelesaikan penelitian ini.

\section{Daftar Pustaka}

Bonneff, Marcel. (2008). Komik Indonesia. Jakarta: Kepustakaan Populer Gramedia. Damono, Sapardi Djoko. (2018). Alih Wahana. Jakarta: PT. Gramedia Pustaka Utama.

Gunawan, Imam. (2014). Metode Penelitian Kualitatif: Teori dan Praktik. Jakarta: PT Bumi Aksara.

https://upload.wikimedia.org/wikipedia/id/6/69/Gatotkaca_Surakarta.JPG (diakses pada 18 Juli 2019)

https://www.ciayo.com/id/comic/garudayana/hutan-kalpataru

(diakses pada 18 Juli 2019)

https://www.deviantart.com/vanguard-zero/art/Garudayana-Chara-Arjuna149732781(diakses pada 18 Juli 2019)

https://www.deviantart.com/vanguard-zero/art/Garudayana-chara-Gatotkaca147212886_(diakses pada 18 Juli 2019)

https://www.deviantart.com/vanguard-zero/art/Garudayana-chara-Kinara-147210932 (diakses pada 18 Juli 2019)

https://www.deviantart.com/vanguard-zero/art/Garudayana-Comic-Cover130179534 (diakses pada 18 Juli 2019)

Kaelola, Akbar. (2010). Mengenal Tokoh Wayang Mahabharata. Jakarta: Cakrawala. Susanto, Harry Eko. (2018). Komunikasi Manusia: Teori dan Praktik Dalam Penyampaian Gagasan. Jakarta: Mitra Wacana Media. 